\title{
COMPARISON OF DIFFERENT PROCEDURES TO PREDICT UNSATURATED SOIL SHEAR STRENGTH
}

\author{
S.K. Vanapalli and D.G. Fredlund ${ }^{1}$
}

\begin{abstract}
Several procedures have been proposed in the recent years to predict the shear strength of an unsaturated soil. The soil-water characteristic curve has been used as a tool either directly or indirectly in the prediction of the shear strength along with the saturated shear strength parameters in these procedures. This paper provides comparisons between the measured and predicted values of unsaturated shear strength using these procedures for three soils both for limited and large suction ranges. The three soils used in the study for comparisons have different gradation properties, percentages of clay and plasticity index, $I_{p}$ values. The advantages and limitations associated with predicting the shear strength of unsaturated soils using the procedures is discussed in the paper.
\end{abstract}

\section{INTRODUCTION}

A theoretical framework for unsaturated soil mechanics that parallels saturated soil mechanics is available in terms of stress state variables, namely; net normal stress, $\left(\sigma_{n}-u_{a}\right)$, and matric suction, $\left(u_{a}-u_{w}\right)$ where $\sigma_{n}$ is the normal stress, $u_{a}$ is the pore-air pressure an $u_{w}$ is the pore-water pressure. (Fredlund and Rahardjo, 1993). The framework is based on experimental studies that are costly and time consuming. Several advancements have been made in the prediction of the engineering behavior of unsaturated soils in recent years. The soil-water characteristic curve has been found to be a useful tool in the estimation of engineering properties for unsaturated soils. Examples are the coefficient of permeability and the shear strength functions.

Shear strength forms an important engineering property in the design of numerous geotechnical and geo-environmental structures such as earth dams, retaining walls, pavements, liners, covers, etc. Several procedures have been proposed in the literature during the past five years to predict the shear strength of an unsaturated soil.

${ }^{1}$ Department of Civil Engineering, University of Saskatchewan, SK, Canada, S7N 5A9 
These procedures use the soifwater characteristic curve as a tool either directly or indirectly along with the saturated shear strength parameters, $c^{\prime}$ ' and $\phi^{\prime}$, to predict the shear strength function for an unsaturated soil (Vanapalli et al. 1996, Fredlund et al. 1996, Oberg and Sallfors 1997, Khallili and Khabbaz 1998 and Bao et al. 1998).

The philosophy used in each of the prediction procedures proposed by these investigators is different. Comparisons have been provided between predicted and measured values of shear strength for a limited suction range for various soils (i.e., between 0 to 500 $\mathrm{kPa})$.

Escario and Juca (1989) measured the soil-water characteristic curves and the shear strength of three soils prior to the time when any proposals had been made for the shear strength functions. The three soils have different gradation properties, percentages of clay and plasticity indices, $I_{p}$. These results are used in this paper to provide comparisons between the predicted and measured shear strength values both for a limited suction range and a large suction range. The study presented in the paper highlights the advantages and limitations associated with the various procedures for predicting the shear strength of unsaturated soils. The simple procedures discussed in this paper are of value in bringing the shear strength theories for unsaturated soils into engineering practice.

\section{EQUATIONS FOR INTERPRETING THE SHEAR STRENGTH OF UNSATURATED SOILS}

Bishop (1959) proposed shear strength equation for unsaturated soils by extending Terzaghi's principle of effective stress for saturated soils. Bishop's original equation can be arranged as shown below.

$\tau=c^{\prime}+\left(\sigma_{n}-u_{a}\right) \tan \phi^{\prime}+\left(u_{a}-u_{w}\right)\left[(\chi)\left(\tan \phi^{\prime}\right)\right]$

where:

$\begin{array}{lll}\tau & = & \text { shear strength of unsaturated soil, } \\ c^{\prime} & = & \text { effective cohesion, } \\ \phi^{\prime} & = & \text { angle of frictional resistance, } \\ \left(\sigma_{n}-u_{a}\right) & = & \text { net normal stress, } \\ \left(u_{a}-u_{w}\right) & = & \text { matric suction, and } \\ \chi & = & \text { a parameter dependent on the degree of saturation }\end{array}$

The value of $\chi$ was assumed to vary from 1 to 0 , which represents the variation from a fully saturated condition to a total dry condition. Several investigators found limitations with respect to the quantification of the parameter $\chi$ both theoretically and experimentally.

Fredlund et al. (1978) have proposed a relationship to explain the shear strength of unsaturated soils in terms two independent stress state variables as shown below:

$\tau=c^{\prime}+\left(\sigma_{n}-u_{a}\right) \tan \phi^{\prime}+\left(u_{a}-u_{w}\right) \tan \phi^{b}$ 
The shear strength contribution due to matric suction, $\phi^{b}$, was initially assumed to be linear based on the analysis of limited results published in the literature. Later experimental studies performed over a large range of suction values have shown that the variation of shear strength with respect to soil suction is non-linear (Gan et al. 1988 and Escario and Juca 1989).

Equation [1] can be applied for both the linear and non-linear variation of shear strength with respect to suction.

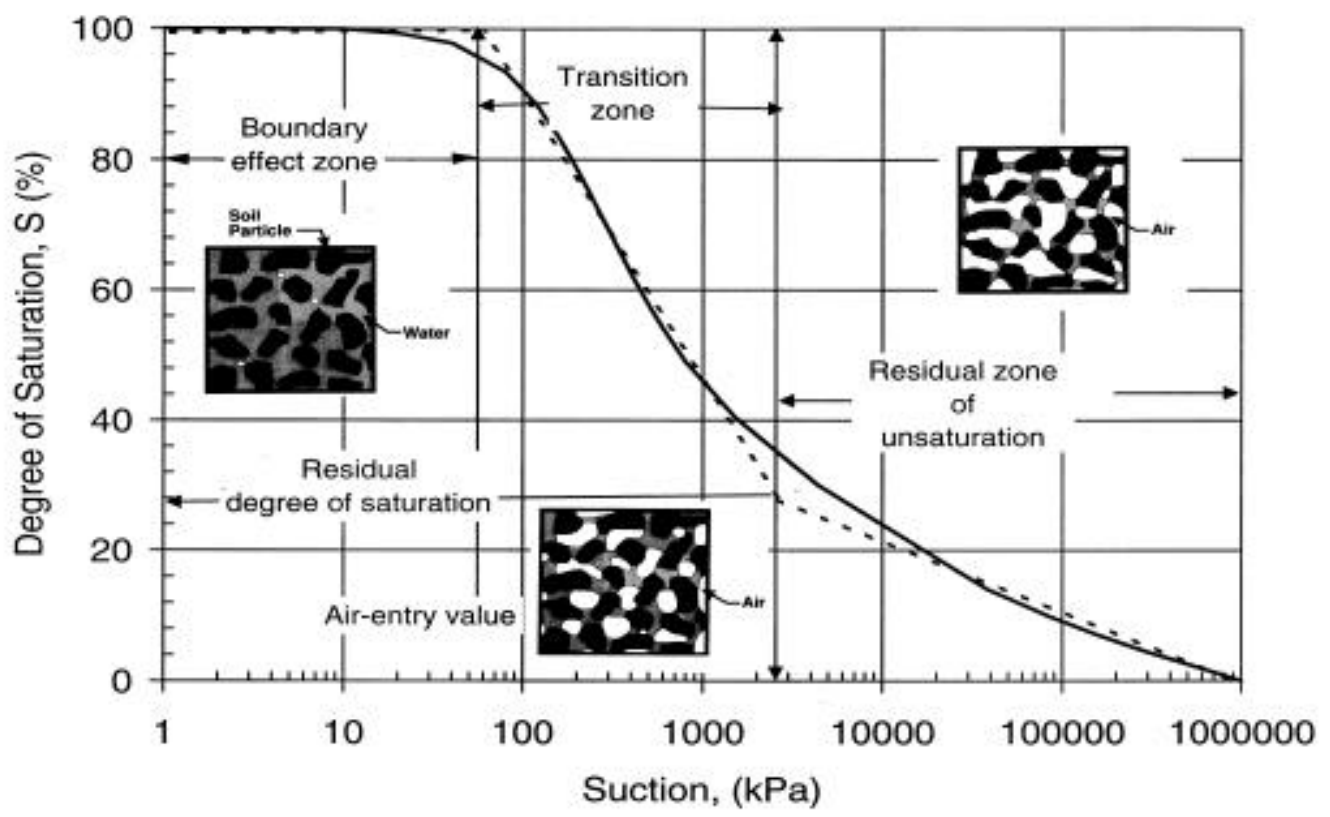

Figure 1. Typical soil- water characteristic curve showing zones of desaturation.

\section{The Relationship between the Soil-Water Characteristic Curve and the Shear Strength of Unsaturated soils}

The soil-water characteristic curve defines the relationship between the soil suction and either the degree of saturation, $S$, or gravimetric water content, $w$, or the volumetric water content, $\theta$ (Figure 1). The soil-water characteristic curve provides a conceptual and interpretative tool by which the behavior of unsaturated soils can be understood. As the soil moves from a saturated state to drier conditions, the distribution of the soil, water, and air phases change as the stress state changes. A typical soil-water characteristic curve with various zones of desaturation are shown in Figure 1.

The wetted area of contact between the soil particles decreases with an increase in the soil suction. There is a relationship between the rate at which shear strength changes in unsaturated conditions to the wetted area of water contact between the soil particles or aggregates. In other words, a relations hip exists between the soil-water characteristic curve and the shear strength of unsaturated soils. 


\section{Different Procedures for Predicting the Shear Strength of an Unsaturated Soil}

Vanapalli et al. (1996) and Fredlund et al. (1996) have proposed a more general, nonlinear function for predicting the shear strength of an unsaturated soil using the entire soilwater characteristic curve (i.e., 0 to $1,000,000 \mathrm{kPa}$ ) and the saturated shear strength parameters as shown below:

$\tau=\left[c^{\prime}+\left(\sigma_{n}-u_{a}\right) \tan \phi^{\prime}\right]+\left[\left(u_{a}-u_{w}\right)\left\{\left(\Theta^{\kappa}\right)\left(\tan \phi^{\prime}\right)\right\}\right]$

where:

$\kappa=$ fitting parameter used for obtaining a best-fit between the measured and predicted values, and

$\Theta=$ normalized water content, $\theta_{\mathrm{w}} / \theta_{\mathrm{s}}$.

The shear strength contribution due to suction constitutes the second part of [Eq. 3], which is:

$\tau_{u s}=\left[\left(u_{a}-u_{w}\right)\left\{\left(\Theta^{\mathrm{K}}\right)\left(\tan \phi^{\prime}\right)\right\}\right]$

Equation [3] can also be written in terms of degree of saturation, $S$, or gravimetric water content, $w$, to predict the shear strength yielding similar results.

The entire soil-water characteristic curve data (i.e., 0 to $1,000,000 \mathrm{kPa}$ ) is required along with the saturated shear strength parameters in the use of Equation [3]. A best-fit soilwater characteristic curve can be obtained in terms of $a, n$, and $m$ parameters using the equation proposed by Fredlund and Xing (1994) which is shown below:

$\theta_{w}(\psi)=\theta_{s}\left[1-\frac{\ln \left(1+\frac{\psi}{h_{r}}\right)}{\ln \left(1+\frac{10^{6}}{h_{r}}\right)}\right]\left[\frac{1}{\ln \left\{\exp (1)+\left(\frac{\psi}{a}\right)^{n}\right\}^{m}}\right]$

where:

$\psi=$ soil suction,

$\boldsymbol{\theta}_{w}=$ volumetric water content,

$\theta_{s}=$ saturated volumetric water content,

$a=$ suction related to the inflection point on the curve,

$n=$ soil parameter related to slope at the inflection point,

$m=$ soil parameter related to the residual water content, and

$h_{r}=$ suction related to the volumetric residual water content, $\boldsymbol{\theta}_{r}$

The shear strength contribution due to suction, $\tan \phi^{b}$ is equal to $\tan \phi$ up to the airentry value of the soil. In other words, the conventional equation for estimating the shear strength of saturated soils can be used up to the air-entry value for unsaturated soils. The shear strength variation with respect to suction is linear in the boundary effect zone. The 
shear strength contribution due to suction, $\tan \phi^{b}$ is less than $\tan \phi$ in the transition zone. Hence, the shear strength variation in this zone is non-linear. The shear strength value gradually starts dropping at high values of suction and reaches saturated shear strength value at $1,000,000 \mathrm{kPa}$ using this equation. Equation [3] is useful to predict the shear strength of unsaturated over the entire range of suction values of 0 to $1,000,000 \mathrm{kPa}$ (i.e., from a fully saturated condition to a total dry cond ition). Analysis of experimental results presented and shown in the Figures 3 to 8 of this paper using Equation [3] will be referred as Procedure 1.

Vanapalli et al. (1996) proposed another equation for predicting the shear strength of unsaturated soils without using the fitting parameter, $\kappa$ The equation is given below:

$\tau=c^{\prime}+\left(\sigma_{n}-u_{a}\right) \tan \phi^{\prime}+\left(u_{a}-u_{w}\right)\left[\left(\frac{\boldsymbol{\theta}_{w}-\boldsymbol{\theta}_{r}}{\boldsymbol{\theta}_{s}-\boldsymbol{\theta}_{r}}\right) \tan \phi^{\prime}\right]$

where:

$\theta_{w}=$ volumetric water content,

$\theta_{s}=$ saturated volumetric water content, and

$\theta_{r}=$ residual volumetric water content.

Equation [6] can also be written in terms of degree of saturation, $S$, or gravimetric water content, $w$, to predict the shear strength yielding similar results. To use this equation the residual volumetric water content, $\boldsymbol{\theta}_{r}$, has to be estimated from the soil-water characteristic curve.

A graphical procedure can be used to define the residual state of saturation (Figure 1). The procedure involves first drawing a tangent line through the inflection point on the straight-line portion of the soil-water characteristic curve. The residual saturation can be defined as the point where the line extending from 1,000,000 $\mathrm{kPa}$ along the curve intersects the previous line. A computational technique can also be used to determine the residual suction value. More details about the computational technique are available in Vanapalli et al. (1998). The shear strength of soil may start to decrease beyond the residual state conditions. Analysis of experimental results presented and shown in the figures of this paper using Equation [6] are referred as Procedure 2.

Both the Procedures 1 and 2 are consistent with the stress state variable approach satisfying the continuum mechanics concepts. The form of the equation is similar to the Fredlund et al. (1978) equation (i.e., Equation 2).

Oberg and Sallfors (1997) proposed an equation for predicting the shear strength of primarily non-clayey soils such as sands and silts. The proposed equation can be rearranged as follows:

$\tau=c^{\prime}+\left(\sigma_{n}-u_{a}\right) \tan \phi^{\prime}+\left(u_{a}-u_{w}\right)\left[(S)\left(\tan \phi^{\prime}\right)\right]$ 
The $\chi$ parameter proposed by Bishop is replaced by the degree of saturation, $S$, in Eq. [7]. The author's state that the $\chi$-factor proposed by Bishop reflects the fraction of the pore area that is occupied by water (i.e., $A_{w} / A_{t}$ ) which is approximately equal to the degree of saturation, S. Equation [7] has not been experimentally verified on soils through the measurement of the shear strength and the degree of saturation at the point of failure in the specimens.

Equation [7] suggests that there is a one to one relationship between the degree of saturation, $S$, and the area of water contact along the shear plane in the soil. Analysis of experimental results presented and shown in the figures of this paper using Equation [7] are referred as Procedure 3.

Khallili and Khabbaz (1998) have extended Bishop's equation (1959) (i.e., Equation 1) for predicting the shear strength of an unsaturated soil. An empirical constant has been suggested for the parameter, $\chi$ in Equation 1 as given below:

$$
\chi=\left\{\frac{\left(u_{a}-u_{w}\right)_{f}}{\left(u_{a}-u_{w}\right)_{b}}\right\}^{-0.55}
$$

where:

$\left(u_{a}-u_{w}\right)_{f} \quad=$ matric suction in the specimens at failure conditions,

$\eta \quad=$ a value equal -0.55 was suggested based on 13 soils data published in the literature

The required parameters for predicting the shear strength of unsaturated soils based on Khallili and Khabbaz (1998) approach is the air-entry value, $\left(u_{a}-u_{w}\right)_{b}$ of the soil and the saturated shear strength parameters. Analysis of experimental results presented and shown in the figures of this paper using Khallili and Khabbaz (1998) procedure is referred as Procedure 4.

Practicing engineers are most interested in the shear strength behavior in the transition zone (Figure 1). The transition zone lies between the air-entry value and the residual zone of saturation (Vanapalli et al. 1996a). The variation of the soil-water characteristic curve behavior in the transition zone is linear on a semi-logarithmic plot (i.e., variation of degree of saturation, $S$, or volumetric water content, $\theta$, or gravimetric water content, $w$ versus logarithm of soil suction). Bao et al. (1998) suggest another equation for predicting the unsaturated shear strength taking into account of the linear variation of the soil-water characteristic curve in the transition zone as below:

$\tau=c^{\prime}+\left(\sigma_{n}-u_{a}\right) \tan \phi^{\prime}+\left(u_{a}-u_{w}\right)\left[\xi-\zeta \log \left(u_{a}-u_{w}\right)\right] \tan \phi^{\prime}$

where:

$\xi=\frac{\log \left(u_{a}-u_{w}\right)}{\log \left(u_{a}-u_{w}\right)_{r}-\log \left(u_{a}-u_{w}\right)_{b}}$ 
$\zeta=\frac{1}{\log \left(u_{a}-u_{w}\right)_{r}-\log \left(u_{a}-u_{w}\right)_{b}}$

$\left(u_{a}-u_{w}\right)_{r}=$ soil suction at residual water content conditions

The parameter, $\xi$, represents the intercept (i.e., on the abscissa) and the parameter, $\zeta$ represents the slope of the linear part of the soil-water characteristic curve respectively. Bao et al. (1998) suggests use of the expression given below for fitting the soil-water characteristic curve data.

$\frac{\left(\boldsymbol{\theta}_{w}-\boldsymbol{\theta}_{s}\right)}{\left(\boldsymbol{\theta}_{s}-\boldsymbol{\theta}_{r}\right)}=\xi-\zeta \log \left(u_{a}-u_{w}\right)$

The form and philosophy of the Equation [9] for predicting the shear strength of unsaturated soils is similar to Procedure 2 outlined in this paper.

\section{EXPERIMENTAL DATA USED IN THE ANALYSIS}

Escario and Juca (1989) measured the shear strength of three different soils with varying percentages of clay and plasticity indices, $I_{p}$, using modified direct shear equipment. Statically compacted specimens were used in the measurement of shear strength under consolidated drained conditions with different net normal stresses. The shear strength for two soils, namely, Madrid gray clay and Red silty clay was measured for a suction range between 0 to $15,000 \mathrm{kPa}$. The shear strength for Madrid clay sand was measured for a suction range between 0 to $5,000 \mathrm{kPa}$. The properties of three soils used in their testing program are summarized in Table 1 .

Table 1. Summary of soil properties tested by Escario and Juca (1989).

\begin{tabular}{|l|l|l|l|}
\hline & $\begin{array}{l}\text { Madrid } \\
\text { gray clay }\end{array}$ & $\begin{array}{l}\text { Red silty } \\
\text { clay }\end{array}$ & $\begin{array}{l}\text { Madrid clay } \\
\text { sand }\end{array}$ \\
\hline Sand $(\%)$ & 1 & 17 & 87 \\
\hline Silt $(\%)$ & 27 & 48 & 7 \\
\hline Clay $(\%)$ & 72 & 35 & 6 \\
\hline Liquid Limit, $w_{L}(\%)$ & 71 & 33 & 28 \\
\hline Plasticity Index, $I_{p}(\%)$ & 35 & 13.6 & 8 \\
\hline Specific Gravity, $G_{s}$ & 2.64 & 2.66 & 2.71 \\
\hline Void ratio, $e$ & 1.03 & 0.48 & 0.38 \\
\hline
\end{tabular}

Escario and Juca (1989) have also measured the soil-water characteristic curves for the three soils for a suction range between 0 to $15,000 \mathrm{kPa}$. The soil-water characteristic curves were measured with an applied stress of $20 \mathrm{kPa}$ using calibrated springs such that there is a good contact between the specimen and the ceramic stone of the pressure plate apparatus. Figure 2 presents the fitted soil-water characteristic curve data for the entire suction range from 0 to 1,000,000 $\mathrm{kPa}$ using Equation 5 (Fredlund and Xing, 1994). It should 
be noted that the soil-water characteristic curve data in the high suction range were not measured.

The soil-water characteristic curve results suggest that the air-entry and the residual suction values of the soil increases with an increase in the percentage of fines present in the soil. Table 2 summarizes the estimates of air-entry value and the residual suction value based on the construction procedure defined in Figure 1.

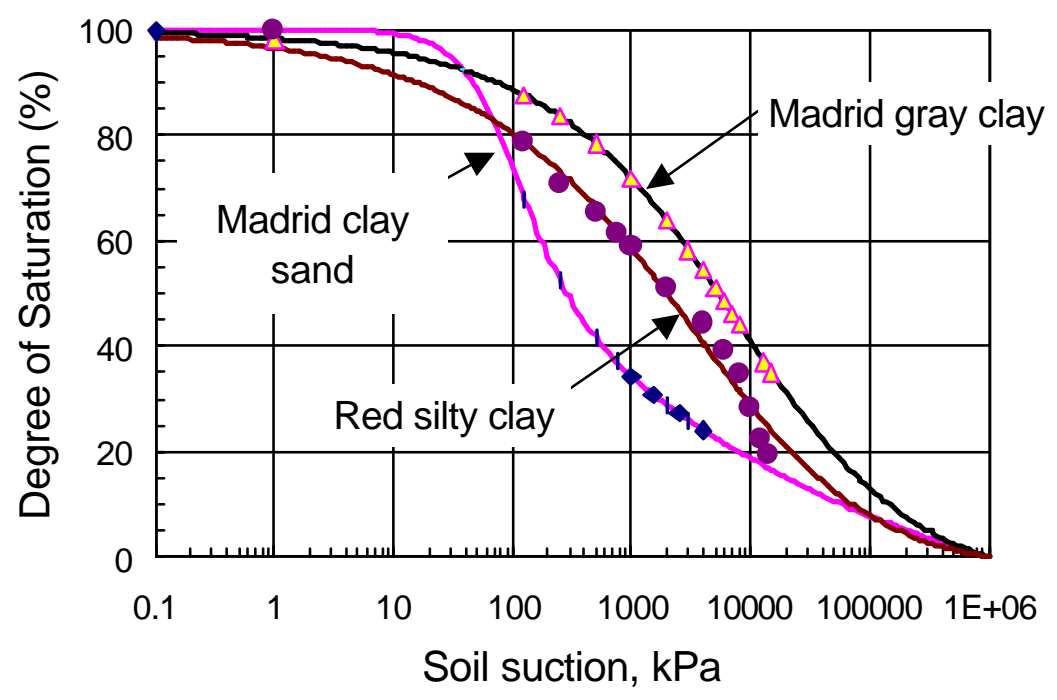

Figure 2. Soil-water characteristic curves for three soils tested by Escario and Juca (1989).

Table 2. Summary of the saturated shear strength parameters and the soil water characteristic curve data

\begin{tabular}{|l|l|l|l|}
\hline & $\begin{array}{l}\text { Madrid } \\
\text { gray clay }\end{array}$ & $\begin{array}{l}\text { Red silty } \\
\text { clay }\end{array}$ & $\begin{array}{l}\text { Madrid clay } \\
\text { sand }\end{array}$ \\
\hline Air-entry value, $\left(u_{a}-u_{w}\right)_{b}, \mathrm{kPa}$ & 110 & 40 & 30 \\
\hline Residual suction, $\psi \boldsymbol{\psi}, \mathrm{kPa}$ & 40,000 & 33,000 & 12,000 \\
\hline Residual degree of saturation, $(\%)$ & 23 & 16 & 17.6 \\
\hline $\begin{array}{l}\text { Fitting parameter, } \kappa(\mathrm{Procedure} 1 \mathrm{using} \\
\text { Equation } 3)\end{array}$ & 2.8 & 1.9 & 1.65 \\
\hline Effective cohesion, $c^{\prime}, \mathrm{kPa}$ & 30 & 20 & 40 \\
\hline Effective angle of internal friction, $\phi$ ' (degrees) & 25.3 & 34 & 39.5 \\
\hline Net normal stress, $\left(\sigma-u_{a}\right), \mathrm{kPa}$ & 300 & 120 & 120 \\
\hline Saturated shear strength, $\mathrm{kPa}$ & 173.3 & 96.3 & 138.9 \\
\hline
\end{tabular}

The comparisons between the predicted and measured shear strength values are presented using the four different procedures discussed in earlier sections (i.e., Figures 3 to 8). These comparisons are provided both for a limited suction range and as well as a large suction range. The key information required for predicting the shear strength of unsaturated 
soils using the procedures, along with the saturated shear strength parameters is summarized in Table 2.

\section{ANALYSIS OF RESULTS}

Several parameters such as initial compaction water content and the stress state influence the soil-water characteristic curve behavior (Vanapalli et al. 1999). It would appear that the shear strength contribution due to suction can be more accurately estimated using the soil-water characteristic curve that has been determined taking into account the influence of the stress state and the initial water content conditions. The soil- water characteristic curves are conventionally determined in the laboratory only with the application of a nominal normal stress or without the application of any applied vertical stress.

Vanapalli et al. (1998b) studies have shown that the shear strength of Indian Head till specimens can be predicted with a reasonable degree of accuracy using the soil-water characteristic curves that have been measured without considering the influence of stress state. Procedures 1 and 2 presented in this paper were used for analyzing the results. The Atterberg limits of the Indian Head till were as follows: liquid limit, $w_{L}$ of $35.5 \%$ and plasticity index, $I_{p}$ of $18.7 \%$. The fractions of sand, silt, and clay were $28 \%, 42 \%$ and $30 \%$ respectively.

The predicted and measured shear strength values are compared for the three soils in this paper are; namely, Madrid gray clay, Red silty clay and Madrid clay sand. The shear strength of these soils were tested with different net normal stresses (Table 2). The soil-water characteristic curves measured with $20 \mathrm{kPa}$ stress were used in the analyses (Figure 1).

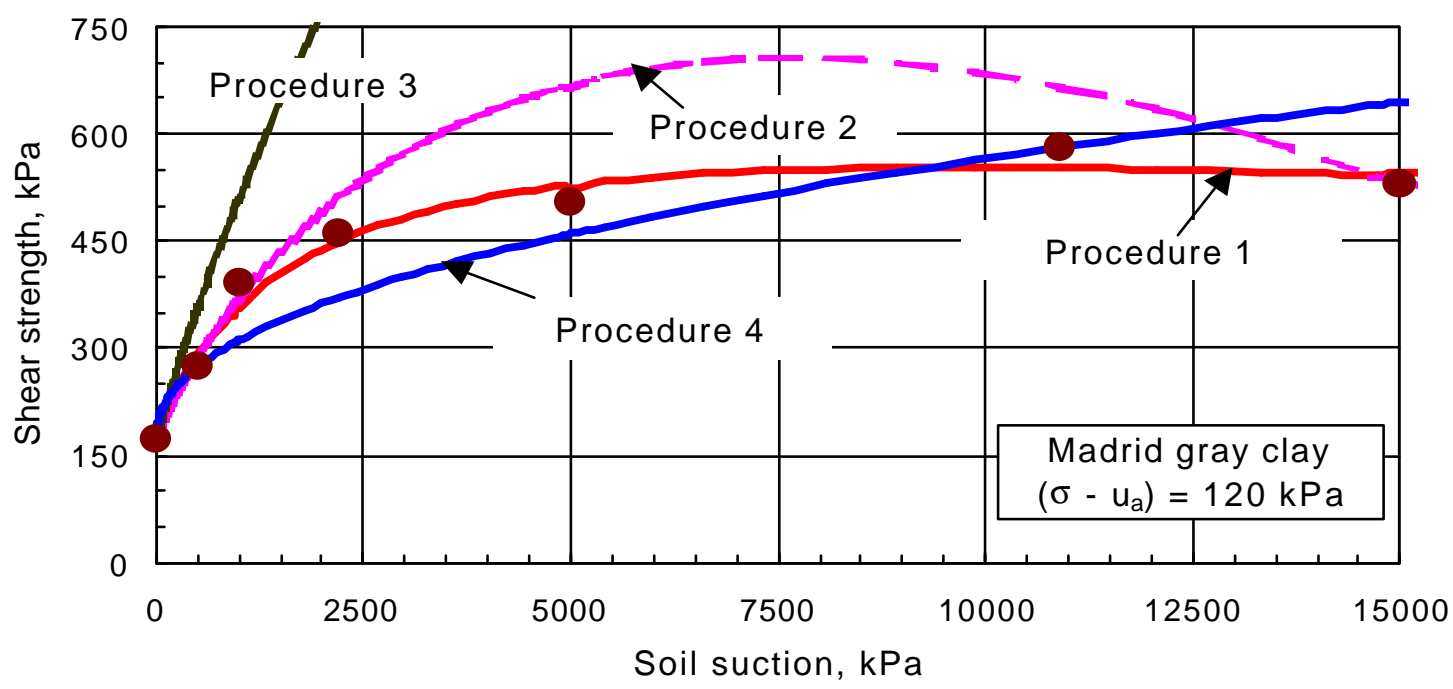

Figure 3. Comparison of predicted and measured shear strength values for Madrid gray clay using different procedures for a large suction range. 


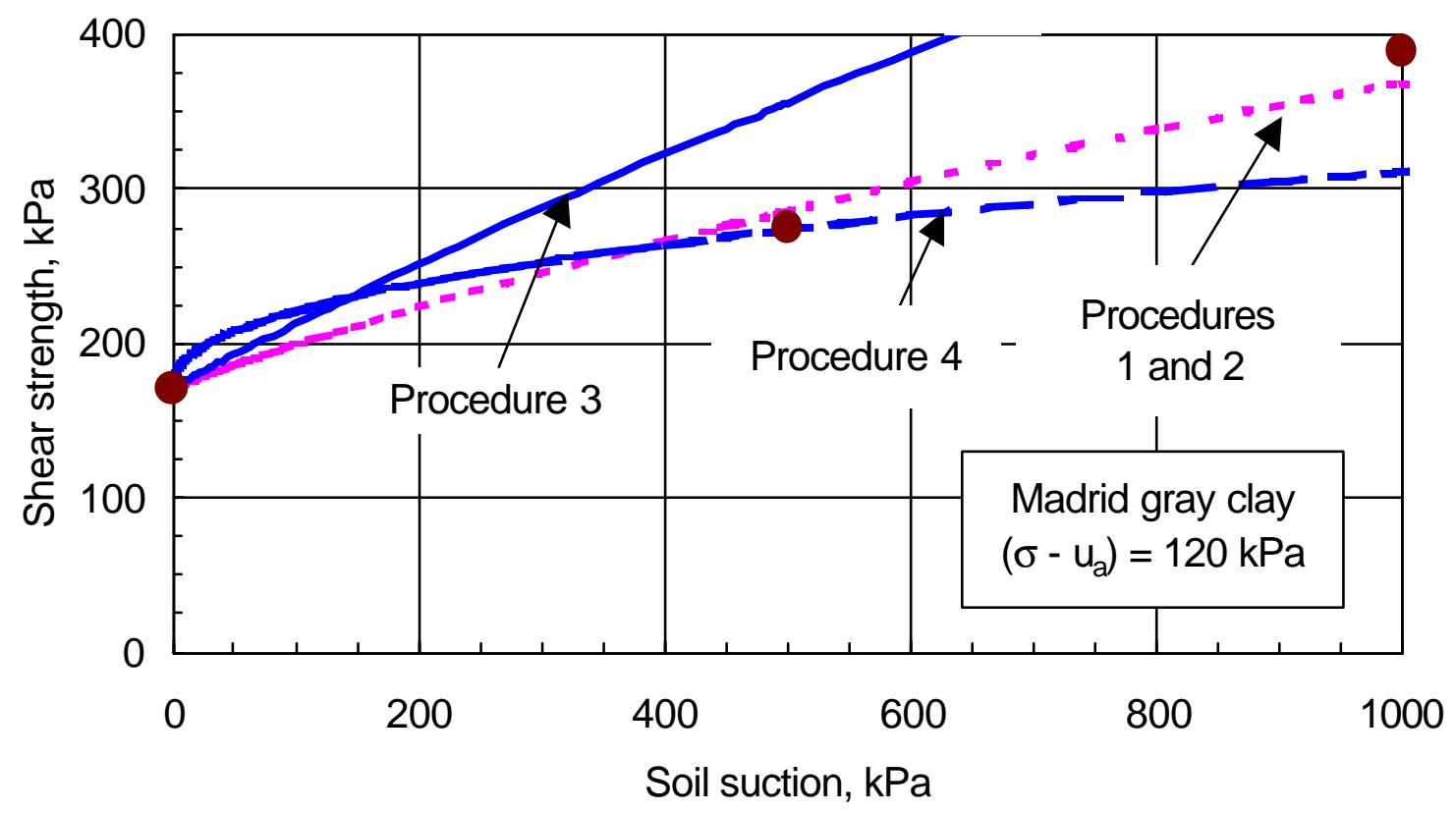

Figure 4. Comparison of predicted and measured shear strength values for Madrid gray clay using different procedures for a large suction range.

Figure 3 shows comparisons between the predicted and measured shear strength values for Madrid gray clay using the four different procedures discussed in the paper for a suction range between 0 to $15,000 \mathrm{kPa}$. The continuous lines in the figure represent the predicted shear strength values and the symbols are the measured shear strength values. There is a good comparison between the predicted and measured values of the shear strength for the suction range of 0 to $15,000 \mathrm{kPa}$ using Procedure 1 (Figure 3). A fitting parameter value of $\kappa$ equal to 2.8 was used for obtaining these predictions using Equation [3].

Figure 4 shows comparisons between predicted and measured shear strength values for a limited suction range of 0 to $1,000 \mathrm{kPa}$. Procedures 2 and 4 along with Procedure 1 provide good comparisons between the measured and predicted values of shear strength.

Figure 5 shows the comparison between the measured and predicted shear strength values for Red silty clay for the suction range 0 to $15,000 \mathrm{kPa}$. Procedure 1 provides good comparisons for the suction range of 0 to $15,000 \mathrm{kPa}$. Procedures 2, 3 and 4 do not provide good comparisons. These observations are consistent with the earlier observations for Madrid gray clay. 


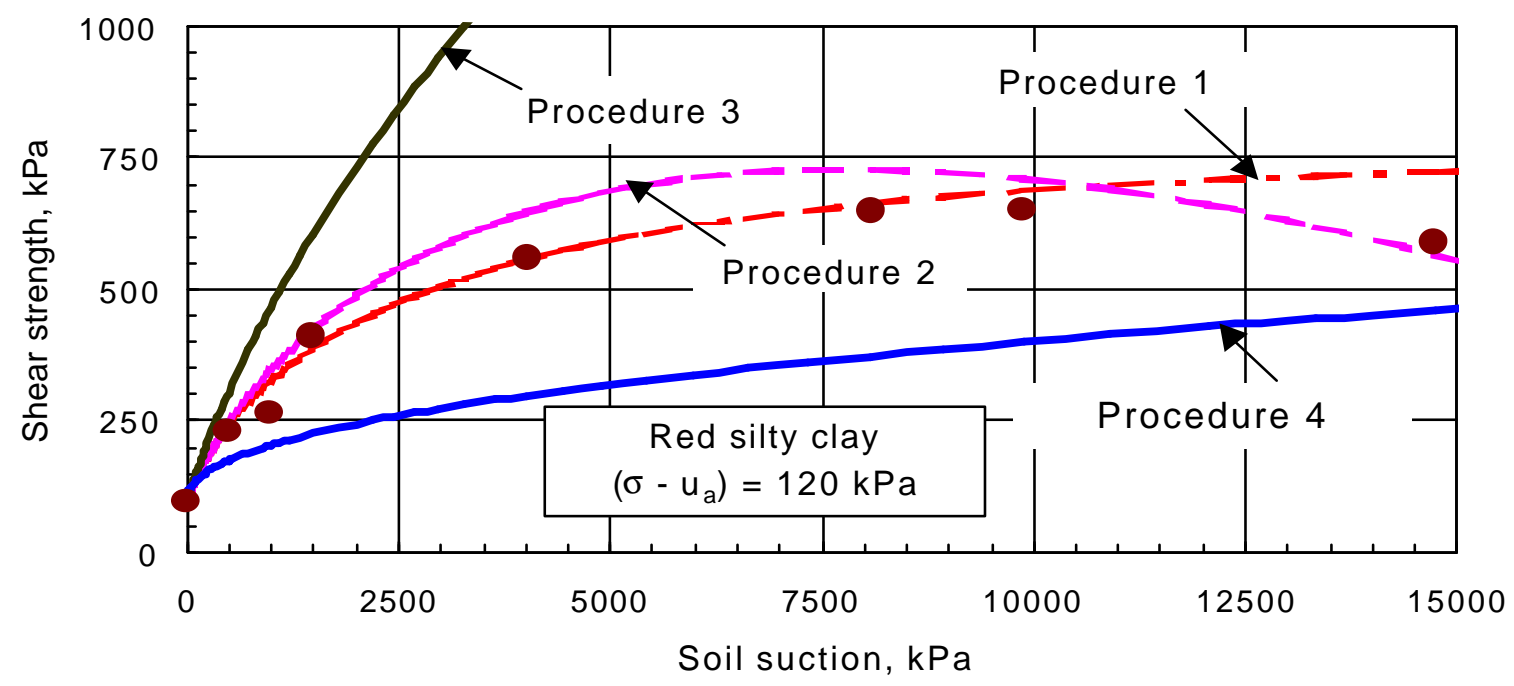

Figure 5. Comparison of predicted and measured shear strength values for Red silty clay using different procedures for a la rge suction range.

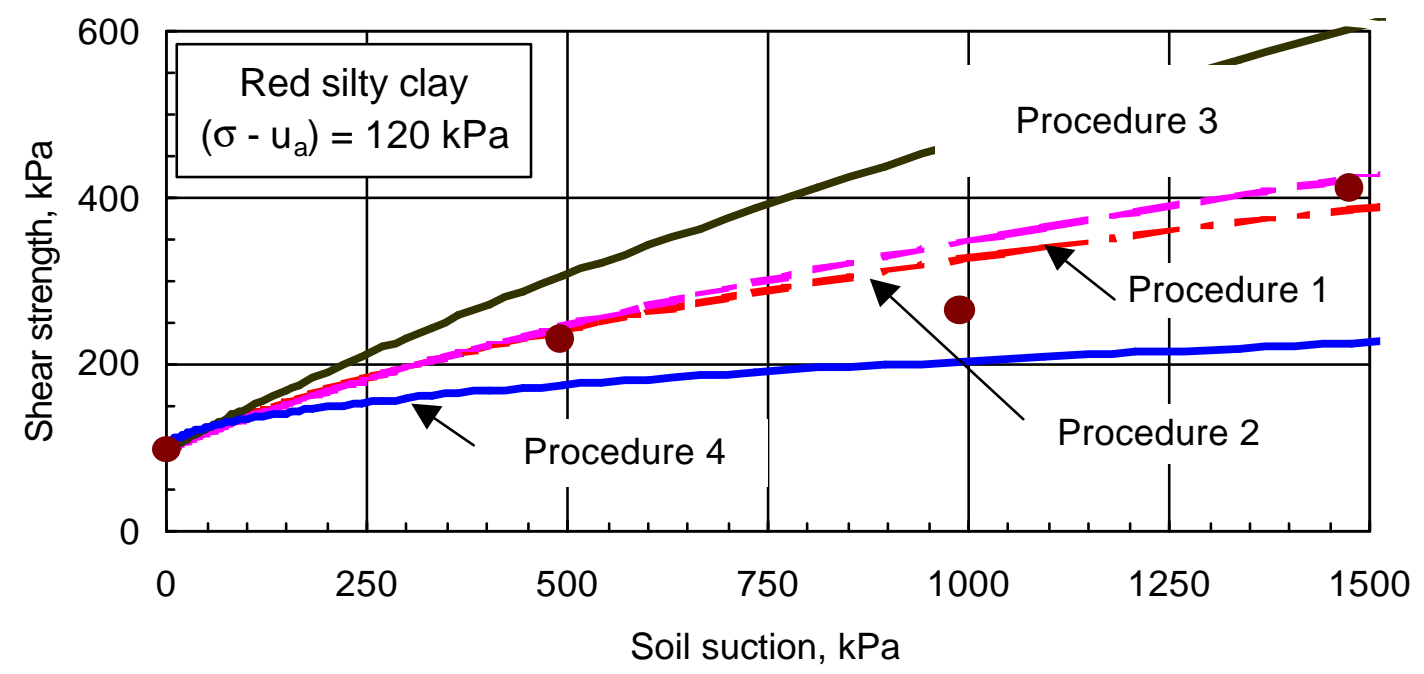

Figure 6. Comparison of predicted and measured shear strength values for Red silty clay using different procedures for a suction range between 0 to $1,500 \mathrm{kPa}$.

Figure 6 shows the comparison between predicted and measured shear strength values for Red silty clay for a limited suction range between 0 to $1,500 \mathrm{kPa}$. Procedures 3 and 4 do not provide good comparisons. Procedure 2 provides reasonably good comparisons for a suction range between 0 to $1,500 \mathrm{kPa}$. 


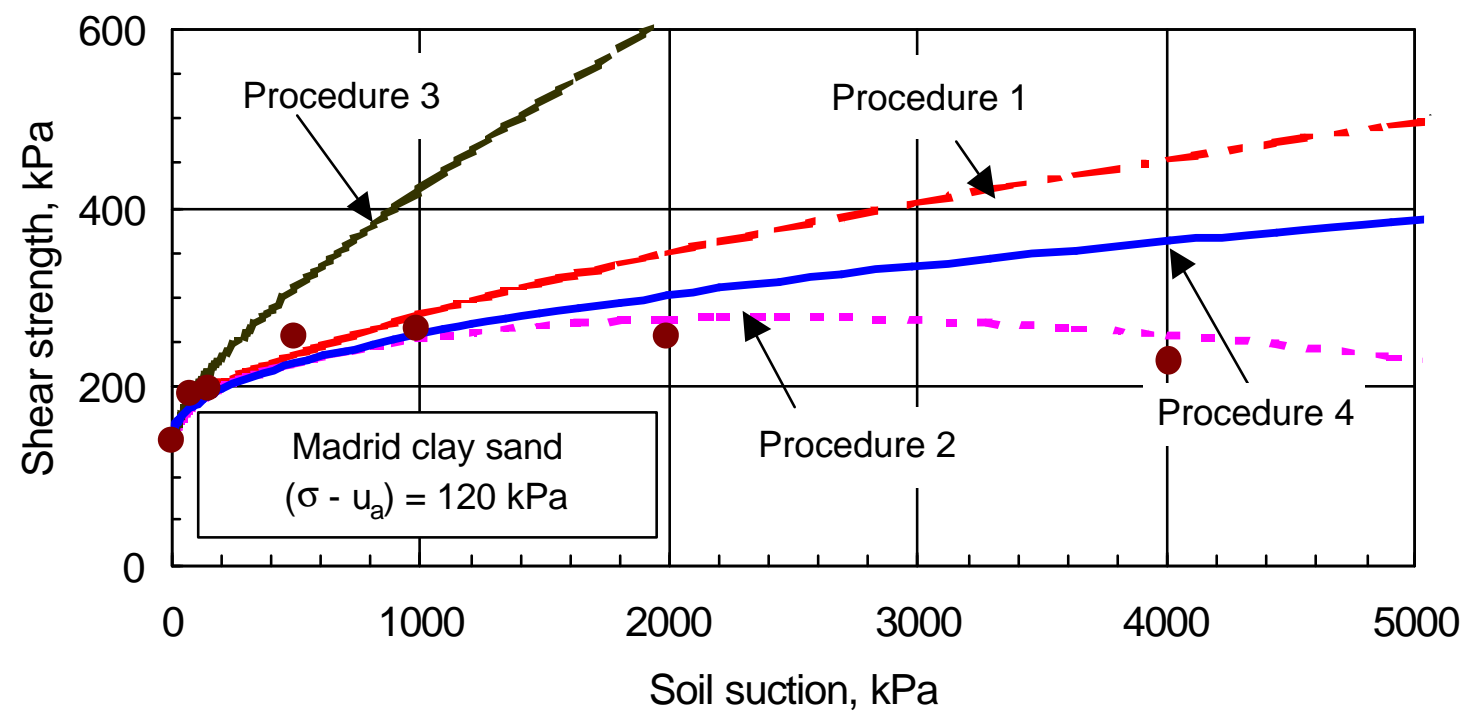

Figure 7. Comparison of predicted and measured shear strength values for Madrid clay sand using different procedures for a large suction range.

Figure 7 provides comparison between the measured and predicted shear strength values for Madrid clay sand for the suction range 0 to 5,000 $\mathrm{kPa}$. Procedure 2 provides good comparison for the suction range of 0 to $5,000 \mathrm{kPa}$.

Figure 8 shows the comparison between predicted and measured shear strength values for Madrid clay sand for a limited suction range between 0 to $1,000 \mathrm{kPa}$. Procedure 1 , 2 , and 4 provide reasonably good comparisons.

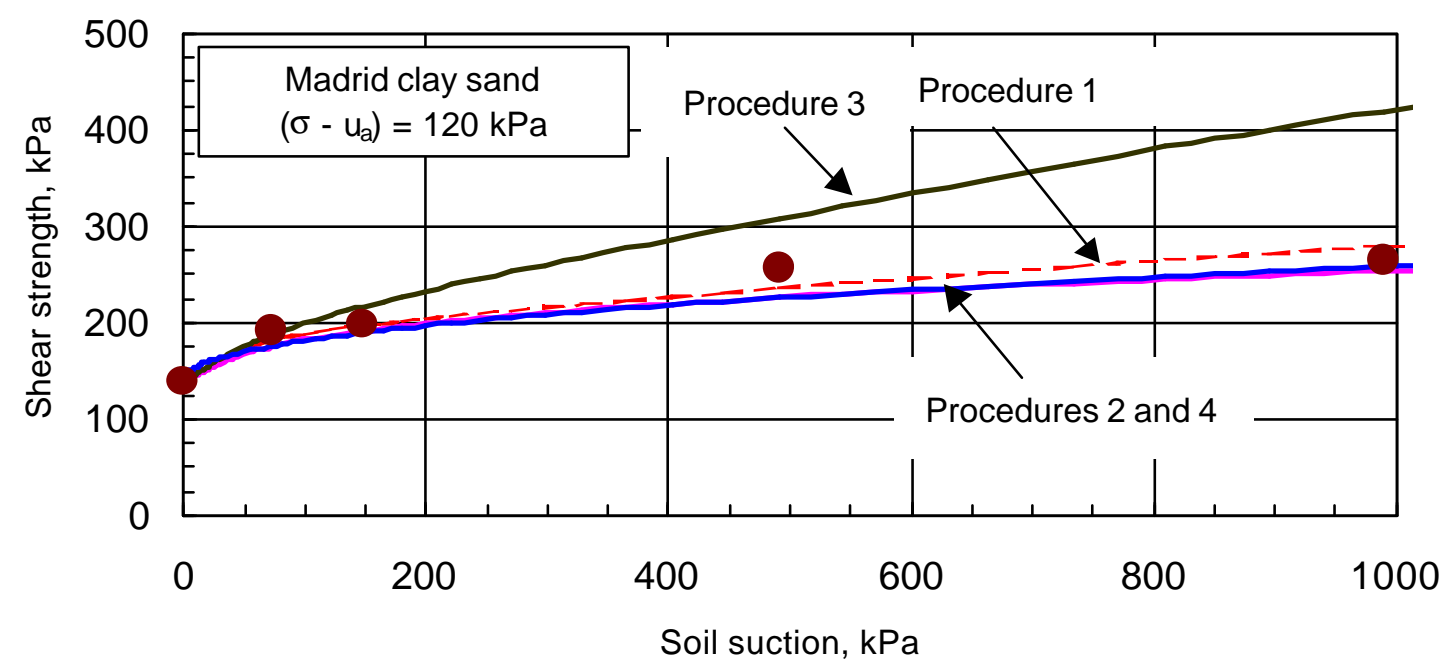

Figure 8. Comparison of predicted and measured shear strength values for Madrid clay sand using different procedures for a suction range between 0 to $1,000 \mathrm{kPa}$. 


\section{Summary and Conclusions}

Comparisons between the measured shear strength and predicted shear strength values for three different soils are presented. Four different procedures available in the literature for predicting the shear strength are used both for limited and large suction ranges.

Procedure 1 provides good comparisons between the measured and predicted shear strength values for limited suction ranges between 0 to $1,500 \mathrm{kPa}$ for all the three soils presented in this paper. Unsaturated soil behavior is of practical interest in this suction range. Good comparisons were also observed for two of the three soils for even for a large suction range. This procedure provides better predictions in comparison to the other procedures.

Figure 9 shows the relationship between the fitting parameter, $\kappa$, and plasticity index, $I_{p}$. Three points of $\kappa$ versus $I_{p}$ relationship were obtained from the study presented in this paper (Table 2). The other two points were based on the studies presented by Vanapalli et al. (1996) using Indian Head and Wulfsohn et al. (1996) using a non-plastic soil. A value of $\kappa$ equal 2.3 provided good correlation between the measured and predicted values of shear strength for Indian Head till with a plasticity index, $I_{p}$, of 18.7. A value of $\kappa$ equal 1 provided good correlation between predicted and measured values of shear strength for the non-plastic soil. The fitting parameter $\kappa$ may be influenced by other parameters such as soil structure, nature of soil (i.e., slurry consolidated, dynamically compacted or statically compacted, natural) etc. More studies are necessary to establish the uniqueness of this relationship. Correlation such as shown in Figure 9 may be possible with other soil constants.

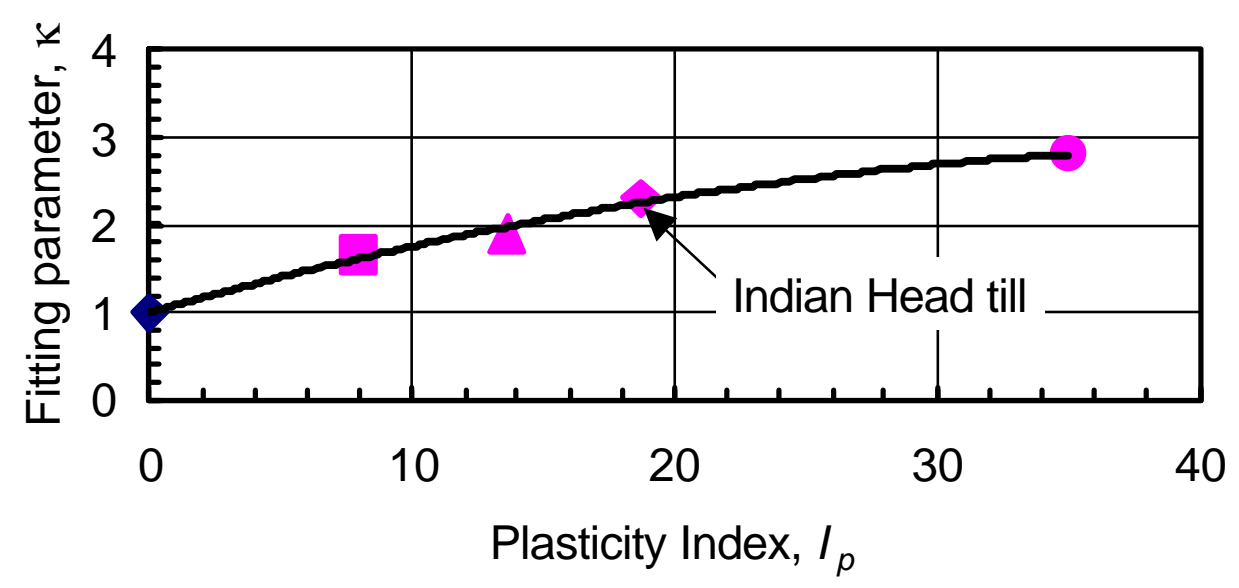

Figure 9. The relationship between the fitting parameter, $\varsigma$ and plasticity index, $I_{p}$

Procedure 2 is provides good comparisons between measured and predicted values for the three soils analyzed in this paper for a limited suction range between 0 to $1,500 \mathrm{kPa}$. However, the comparisons were not good for predicting the shear strength over a large suction range for two soils. This may be attributed to the possible errors in the estimation of 
residual suction value from the construction procedure using limited soif water characteristic curve data.

Procedure 3 does not provide good relations both for limited and as well large suctions ranges for the comparisons undertaken in the study presented in this paper. Figure 8 shows reasonable comparisons for a limited suction range between 0 to $200 \mathrm{kPa}$ for Madrid clay sand.

Procedure 4 provides reasonable estimates for predicting the shear strength of two of the three soils analyzed in the low suction range but does not provide good comparisons for large suction ranges.

The studies presented in this paper show promise of using the procedures predicting the shear strength of an unsaturated soil using the soil-water characteristic curve and the saturated shear strength parameters. More experimental studies are necessary on different types of soils to better understand the shear strength behavior of unsaturated soils and develop better prediction procedures.

\section{REFERENCES}

Bao, C.G., Gong, B. and Zhan, L. 1998. Properties of unsaturated soils and slope stability of expansive soil. Keynote Lecture. UNSAT 98, $2^{\text {nd }}$ International Conference on Unsaturated Soils, Beijing.

Wulfsohn, D., Adams, B.A. and Fredlund, D.G. 1996. Application of unsaturated soil mechanics for agricultural conditions, Canadian Agricultural Engineering, Vol. 38, No. 3, pp. 173-181.

Bishop, A.W. 1959. The principle of effective stress. Tecknish Ukebland, 106(39): 859-863.

Escario, V. and Juca. 1989. Shear strength and deformation of partly saturated soils. Proceedings of the $12^{\text {th }}$ International Conference on Soil Mechanics and Foundation Engineering, Rio de Janerio, 2: 43-46.

Fredlund, D.G., Morgenstern, N.R., and Widger, R.A. 1978. The shear strength of unsaturated soils. Canadian Geotechnical Journal, 15: 313-321.

Fredlund, D.G. and Rahardjo, H. 1993. Soil mechanics for unsaturated soils. John Wiley and Sons Inc., New York.

Fredlund, D.G. and Xing, A. 1994. Equations for the soil-water characteristic curve. Canadian Geotechnical Journal. 31: 517-532.

Fredlund, D.G., Xing, A., Fredlund, M.D., and Barbour, S.L.1996. The relationship of the unsaturated soil shear strength to the soil-water characteristic curve. Canadian Geotechnical Journal. 33: 440-448.

Gan, J.K.M. and Fredlund, D.G. 1988. Multistage direct shear testing of unsaturated soils. American Society for Testing Materials, Geotechnical Testing Journal, 11(2): 132-138.

Khallili, N. and Khabbaz, M.H. 1998. A unique relationship for the determination of the shear strength of unsaturated soils. Geotechnique , 48(5); 681-687.

Oberg, A. and Sallfors, G. 1997 Determination of shear strength parameters of unsaturated silts and sands based on the water retention curve, Geotechnical Testing Journal, GTJODJ, 20(1): 40-48. 
Terzaghi, K. 1943. Theoretical soil mechanics. Wiley Publications, New York.

Vanapalli, S.K., Fredlund D.G., Pufahl, D.E. and Clifton, A.W. 1996. Model for the prediction of shear strength with respect to soil suction. Canadian Geotechnical Journal, 33: 379-392.

Vanapalli, S.K., Sillers, W.S., and Fredlund, M.D. 1998a. The meaning and relevance of residual water content to unsaturated soils. 51st Canad ian Geotechnical Conference, 1998, Edmonton, pp. 101-108.

Vanapalli, S.K., Pufahl, D.E., and Fredlund, D.G. 1998b. The effect of stress state on the soil-water characteristic curve behavior of a sandy-clay till. 51st Canadian Geotechnical Conference, 1998, Edmonton, pp. 81-86.

Vanapalli, S.K., Fredlund, D.G. and Pufahl, D.E. 1999. The influence of soil structure and stress history on the soil-water characteristics of a compacted till. Geotechnique, Vol. 49: 143-159. 